\title{
Novel Treatment Options in Childhood Bone Diseases
}

\author{
Sončka Jazbinšek ${ }^{a}$ Maša Koce ${ }^{a}$ Primož Kotnik $^{a, b}$ \\ ${ }^{a}$ Division of Pediatrics, Department of Pediatric Endocrinology, Diabetes and Metabolism, University Medical Centre

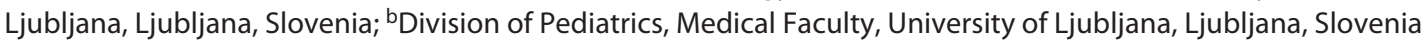

\section{Keywords}

Denosumab · Burosumab · Vosoritide · Bone disorders · Children

\begin{abstract}
Background: Several novel treatment options have recently become available in childhood bone diseases. The purpose of this article is to provide an update on some of the therapeutic agents used in the treatment of pediatric osteoporosis, X-linked hypophosphatemic rickets, and achondroplasia $(A C H)$. Summary: Vitamin D3 and Ca supplementation remains the basis of childhood osteoporosis treatment. Bisphosphonate (BP) therapy is the main antiresorptive therapeutic option, while denosumab, a human monoclonal IgG2 antibody with high affinity and specificity for a primary regulator of bone resorption - RANKL, represents a possible alternative. Its potent inhibition of bone resorption and turnover process leads to continuous increase of bone mineral density throughout the treatment also in the pediatric population. With a half-life much shorter than BPs, its effects are rapidly reversible upon discontinuation. Safety and dosing concerns in children remain. Novel treatment options have
\end{abstract}

recently become available in two rare bone diseases. Burosumab, a monoclonal antibody against FGF-23, has been approved for the treatment of children with X-linked hypophosphatemic rickets older than 1 year. It presents an effective, more etiology-based treatment for rickets compared to conventional therapy, without the need for multiple daily oral phosphate supplementation. Its long-term efficacy and safety are currently being investigated. After years of anticipation, a novel treatment option for $\mathrm{ACH}$ has become available. C-type natriuretic peptide analog vosoritide effectively increases proportional growth and has a reasonable safety profile in children $>2$ years. Its effect on other features of the disease and the final height is yet to be determined. Several other treatment options for $\mathrm{ACH}$ exploring different therapeutic approaches are currently being investigated. Key Messages: Denosumab is effective in the treatment of childhood-onset osteoporosis; however, further studies are necessary to determine the optimal treatment protocol. Burosumab is more etiology-based and convenient in comparison to conventional treatment of X-linked hypophosphatemic rickets in children and adults. Vosoritide importantly changes the natural course of achondroplasia, at least in the short term.
Karger@karger.com www.karger.com/hrp (c) 2022 S. Karger AG, Base 


\section{Pediatric Osteoporosis}

Osteoporosis is a disease characterized by low bone mass and/or an alteration in bone microarchitecture predisposing to an increased risk of fracture. According to the current guidelines, diagnosis of osteoporosis in the pediatric population requires the presence of clinically significant fracture history together with low bone mineral content or density ( $Z$-score $\leq-2.0$, adjusted for age, gender, and body size). Making the diagnosis remains challenging especially in patients with underlying bone fragility conditions $[1,2]$. As $90 \%$ of bone mass is accrued in childhood and adolescent years which further influences the risk of fracture and osteoporosis throughout the life span, identification, and treatment of pediatric patients, who may benefit from pharmaceutical interventions is extremely important $[3,4]$.

The imbalance favoring osteoclast/bone-resorbing to osteoblast/bone-forming activity leads to poor bone health. Two major pathways, receptor activator of nuclear factor kappa-B ligand (RANKL)/osteoprotegerin and Wnt, play a key role in the bone remodeling process. They have been found altered not only in primary bone disorders but also in several other diseases in which bone health is also compromised, such as type 1 diabetes, alkaptonuria, hemophilia A, 21-hydroxylase deficiency, and Prader-Willi syndrome [5]. Primary osteoporosis in childhood is a rare entity, caused by primary bone diseases such as osteogenesis imperfecta, idiopathic juvenile osteoporosis, and osteoporosis-pseudo-glioma syndrome. Additionally, it is seen in connective tissue disorders and other conditions, such as homocystinuria, polyostotic fibrous dysplasia, hypophosphatasia, and Cole-Carpenter syndrome. The causes for secondary osteoporosis are numerous, including adverse effects of medication, immobilization, diseases associated with chronic inflammation, malnutrition, and endocrine disorders. With advances in medical care improving survival outcomes, its prevalence in the pediatric population has recently increased [6]. In addition, obesity in this age group is associated with compromised site-specific bone health and increased fracture risk [7].

Current preventive and therapeutic measures include adequate vitamin $\mathrm{D}$ and calcium intake, optimizing the management of the underlying conditions, and resolving risk factors associated with low BMD [6]. In order to prevent rickets and osteomalacia, the latest guidelines recommend vitamin D supplementation of $400 \mathrm{IU} /$ day for infants up to 12 months of age and $600 \mathrm{IU} /$ day for children and adolescents. Adequate dietary calcium intake to prevent rickets in infants from birth to 6 months is 200 $\mathrm{mg} /$ day and $260 \mathrm{mg} /$ day from 6 to 12 months of age [8]. Further on, recommended daily dietary calcium intake is $700 \mathrm{mg}$ for children of $1-3$ years, $1,000 \mathrm{mg}$ for $4-8$, and $1,300 \mathrm{mg}$ for 9-18 [6]. Antiresorptive therapy is used in children with primary osteoporosis or in those with secondary osteoporosis whose risk factors are unlikely to be mitigated. Treatment with intravenous bisphosphonates (BPs) is currently the most widely used and there is growing evidence supporting their use in the pediatric population [6]. BPs in children are given intravenously and have a very long skeletal half-life and this limits their use in children. Therefore, other therapeutical options for the treatment of osteoporosis in children are being explored (Table 1).

\section{Denosumab}

Denosumab is a human monoclonal IgG2 antibody with high affinity and specificity for a primary regulator of bone resorption - RANKL, a transmembrane protein highly expressed in osteoblasts. RANKL promotes the differentiation of osteoclast precursors and activates mature osteoclasts by binding to the RANK receptor. Denosumab prevents the activation of the RANK receptor by binding to RANKL, which leads to impairment of osteoclast formation, function, and possibly survival [9]. It mimics the natural action of osteoprotegerin, an endogenous decoy receptor of RANKL, and by its binding prevents catabolic effects of RANK signaling pathway activation [10].

Denosumab's convenient subcutaneous application together with the rapid reversibility of its action in comparison to BP's long half-life, make it interesting for use in the pediatric population. Denosumab has more powerful inhibitory effects on bone resorption and turnover than BPs, increasing BMD at all skeletal sites, without changing bone microarchitecture and adversely affecting its mineralization $[11,12]$. BMD increases progressively throughout denosumab use in contrast to BP where a plateau is reached after 2-3 years [13]. Additionally, it can be used in patients with renal function impairment, since it is thought to be cleared from the bloodstream through the reticuloendothelial system [14].

To date, the use of denosumab in the pediatric population is only approved for the treatment of giant cell tumors of the bone in skeletally mature adolescents, when the tumor is unresectable, requires morbid surgery, or in metastatic disease (approved by the Food And Drug Administration [FDA] and the European Medicines Agency [EMA]) $[15,16]$. However, it is used off-label for the 
Table 1. List of novel treatment approaches in selected bone disorders

\begin{tabular}{|c|c|c|c|c|}
\hline Disease & Drug (brand nam & $\mathrm{MOA}$ & Study phase & Dose \\
\hline \multirow[t]{2}{*}{ Osteoporosis } & $\begin{array}{l}\text { Denosumab } \\
\left.\text { (Prolia }^{\oplus}, \text { Xgeva }^{\oplus}\right)\end{array}$ & $\begin{array}{l}\text { Monoclonal IgG2 anti-RANKL; blocks } \\
\text { osteoclast maturation and bone turnover }\end{array}$ & $\begin{array}{l}\text { EMA, FDA approved for the treatment } \\
\text { of GCTB in skeletally mature children } \\
\text { and adults }\end{array}$ & $\begin{array}{l}120 \mathrm{mg} \text { SC on days } 1,8,15, \\
\text { and } 28 \text {, and then every } 4 \\
\text { weeks thereafter [16] }\end{array}$ \\
\hline & Odanacatib & Cathepsin K inhibitor; reduces bone resorption & $\begin{array}{l}\text { Phase III clinical trial in adults } \\
\text { terminated early due to side effects, no } \\
\text { clinical trials on pediatric population } \\
\text { [43] }\end{array}$ & NA \\
\hline $\mathrm{XLH}$ & $\begin{array}{l}\text { Burosumab } \\
\left(\text { Crysvita }{ }^{\oplus}\right.\end{array}$ & $\begin{array}{l}\text { Monoclonal lgG1 anti-FGF3; promotes } \\
\text { phosphate reabsorption and increases serum } \\
\text { concentrations of 1,25-dihydroxy } \\
\text { cholecalciferol }\end{array}$ & $\begin{array}{l}\text { EMA, FDA approved for treatment for } \\
\text { children }>1 \text {-year old }\end{array}$ & $\begin{array}{l}0.4 \mathrm{mg} / \mathrm{kg} \mathrm{SC} \text { every } 2-4 \\
\text { weeks [56] }\end{array}$ \\
\hline \multirow[t]{2}{*}{$\mathrm{ACH}$} & $\begin{array}{l}\text { Vosoritide } \\
\left(\text { Voxzogo }^{\oplus}\right)\end{array}$ & $\begin{array}{l}\text { CNP analog; promotes endochondral bone } \\
\text { formation }\end{array}$ & EMA, FDA approved & $15 \mu \mathrm{g} / \mathrm{kg}$ SC daily [77] \\
\hline & TransCon CNP & $\begin{array}{l}\text { Prolonged-release CNP analog; promotes } \\
\text { endochondral bone formation }\end{array}$ & $\begin{array}{l}\text { Phase } 2 \text { clinical trial ongoing } \\
\text { (NCT04085523) }\end{array}$ & NA \\
\hline
\end{tabular}

ACH, achondroplasia; CNP, C-type natriuretic peptide; EMA, European Medicines Agency; GCTB, giant cell tumors of the bone; FDA, Food And Drug Administration; FGF-3, fibroblast growth factor; MOA, mechanism of action; NA, not available; XLH, X-linked hypophosphatemia.

treatment of different pediatric skeletal disorders [17]. In contrast to adults, data on its use in the pediatric population are currently limited to case reports or small series. There are no studies available on the pharmacokinetics and pharmacodynamics in the pediatric population and no guidelines regarding optimal dosing or treatment duration in this age group [18]. In most studies, a protocol with applications of $0.5-1 \mathrm{mg} / \mathrm{kg}$ (with maximal dose of $60 \mathrm{mg}$ ) per 3 months is used; however, treatment dosage, intervals, and duration vary greatly in the published literature. Results of the studies show that the duration of denosumab action in children with the same bone disorder is variable [19].

Applications of denosumab in children and adolescents with osteogenesis imperfecta (receiving $1 \mathrm{mg} / \mathrm{kg}$ every 12 weeks up to 48 weeks) have been shown to effectively suppress osteoclastic activity and increase BMD. The side effects reported in these studies include asymptomatic rebound hypercalcemia in almost all the patients. Additionally, some participants developed hypercalciuria during treatment, and 1 patient developed nephrocalcinosis. Prolonging the interval between treatment applications resulted in a rapid decrease of acquired BMD in some patients $[19,20]$.

A recent case report observed clinical and radiological improvement in a pubertal boy with primary osteoporosis treated with denosumab (receiving $60 \mathrm{mg}$ every 3 months for 30 months). As a side effect, transient hypercalcemia before applications in the second year of treatment was noted [21]. The improvement of BMD was also observed in treating childhood cancer survivors (receiving $1 \mathrm{mg} / \mathrm{kg}$ every 6 months until height-adjusted $Z$ scores of the BMD were $>-1.5$ ). A significant increase of BMD was observed after 1.5 years of treatment; however, 8 (40\%) patients developed hypocalcemia, with 3 of them presenting with neurological symptoms. Hypercalcemia in this study was not observed [22].

Beneficial effects of denosumab use have also been reported in many small series/case reports in pediatric patients with osteoclast bone dysplasia, fibrous dysplasia, spinal aneurysmal bone cysts, Paget's disease, neuromuscular diseases, and in patients with Noonan syndrome with multiple giant cell lesions of the jaw [17, 23-28]. Different protocols for denosumab dosing and frequency of its application were used in each of the studies, nonetheless, all studies observed good clinical and/or radiological response to the treatment. Frequent disturbances in calcium metabolism were reported during the treatment and after its discontinuation, often requiring additional hospitalizations.

There are some potential risks for the use of denosumab in the pediatric population. Its potent bone turnover suppression could potentially affect the bone modeling process in the growing skeleton and compromise bone 
shape and linear growth. Despite discouraging data in preclinical settings reporting inhibitory effects on linear growth and tooth eruption in rodents and primates, limited clinical studies have reported normal linear growth in children during denosumab treatment $[17,20]$. Besides, in 2014, Wang et al. [29] provided histopathologic evidence that denosumab treatment did not appear to adversely affect the activity of growth plates in a growing child. No negative effects on fracture healing have been reported in preclinical studies as well as in scarce clinical studies in the adult and pediatric population, where fracture healing was analyzed [30]. The high incidence of hypercalcemia as a part of bone turnover rebound upon treatment discontinuation reported in the pediatric population presents another setback for its use [19, 21, 3133]. This outcome could be attributed to the higher baseline bone turnover in children, related to their bone modeling process, and/or may also be the result of the mobilization of calcium from treatment-induced sclerotic transverse lines seen in metaphyses of fast-growing long bones in children treated with antiresorptive therapy $[21,33]$. Prolonged, potent antiresorptive therapy (with $\mathrm{BPs}$ and denosumab) in adults is associated with rare complications such as osteonecrosis of the jaw and atypical femoral fractures [34, 35]. In October 2021, the first case of osteonecrosis of the jaw in a skeletally mature adolescent treated with denosumab for giant cell tumors of the bone as a part of a clinical phase 2 study was reported. Osteonecrosis in an adolescent was diagnosed after 3.6 years of treatment, receiving denosumab at a fixed dose of $120 \mathrm{mg}$ on days $1,8,15$, and 28 , and then every 4 weeks, according to the study protocol. Moreover, in the same clinical study, a young adult presented with bilateral femoral cortical stress reaction after 4 years of treatment. All the studied patients ( 2 adolescents and 1 young adult) developed rebound hypercalcemia with acute kidney injury 5.5-7 months after treatment discontinuation [36]. To date, atypical femoral fractures have not been reported in the pediatric population.

\section{Odanacatib}

Odanacatib is a selective inhibitor of cathepsin K, lysosomal cysteine protease, which is highly expressed by the osteoclasts. Cathepsin $\mathrm{K}$ is a major protease responsible for the degradation of type 1 collagen, which constitutes approximately $90 \%$ of the bone organic matrix. Its inhibition results in slowing down the process of bone matrix resorption without substantially inhibiting bone formation [37].
In the preclinical setting, cathepsin $\mathrm{K}$ inhibition resulted in reduced osteoclast-mediated bone resorption without decreasing osteoclast number or inhibiting other osteoclast functions. The process of bone formation was maintained or only transiently decreased. Its use was not found to affect the bone microarchitecture and an increase in spinal and lumbar BMD was reported in multiple animal models. In comparison to BPs and denosumab, the use of cathepsin $\mathrm{K}$ inhibitors has been shown to impair the bone formation process to a lesser degree [3841]. Similar to denosumab, odanacatib action is rapidly reversible upon treatment discontinuation, returning accrued bone mass and density to pretreatment levels, accompanied by a small rebound of bone resorption markers [41]. Described characteristics together with its convenient oral application would make odanacatib an attractive therapy option for the pediatric population. Significant increases in BMD at all sites (lumbar, hip, and femoral), reduced risk of vertebral, non-vertebral, and hip fractures have been reported in postmenopausal women [42, 43]. However, its use in postmenopausal women was associated with a higher incidence of cardiovascular events (stroke and new-onset atrial fibrillation or flutter) and further development of odanacatib was discontinued by its manufacturer in September 2016 [43]. To date, the mechanism or possible relationship between inhibition of cathepsin $\mathrm{K}$ and an increased risk of cardiovascular events has not been elucidated.

\section{X-Linked Hypophosphatemic Rickets}

$\mathrm{X}$-linked hypophosphatemia $(\mathrm{XLH})$ is a rare hereditary metabolic disorder characterized by bone hypomineralization resulting in osteomalacia and skeletal deformities. It affects 1 in 20,000-25,000 children and is the most common amongst hereditary rickets disorders [44, 45]. It is caused by a mutation in the PHEX gene (phosphate regulating endopeptidase homolog $X$-linked gene), which encodes a transmembrane zinc-dependent endopeptidase that is involved in bone and dentin mineralization $[44,46]$. Consequently, it decreases serum phosphate levels due to the increased urinary phosphate loss, upregulation of FGF-23 (fibroblast growth factor 23) (FGF23), and decreased active vitamin D3 levels [47]. In children, this results in short stature, deformations of the weight-bearing joints, rickets, dental complications, such as spontaneous dental abscess, fistulae, and motor development delay [48-50]. In adult patients, quality of life is considerably decreased by bone pain, early osteoarthritis, 
stiffness, osteomalacic pseudofractures, and impaired mobility [50, 51].

Children with XLH are primarily managed by conventional medical treatment; supplementation with oral phosphate $20-60 \mathrm{mg} / \mathrm{kg}$ body weight daily (divided into several daily doses) and active vitamin D3 to improve intestinal absorption of phosphate and prevent secondary hyperparathyroidism $[52,53]$. Conventional treatment is effective in treating XLH, however, it does not decrease FGF-23 levels [45]. Additionally, it is associated with secondary hyperparathyroidism, hypercalciuria, and nephrocalcinosis, which, if left untreated, leads to kidney damage and insufficiency [54]. Furthermore, compliance with this treatment regimen can be a serious issue in some patients [53].

\section{Burosumab}

Burosumab is the first etiologic treatment option that actively increases phosphate levels while also decreasing FGF-23 actions in XLH (Table 1) [49]. It is a monoclonal IgG1 antibody that suppresses the actions of FGF-23. FGF-23 is the key phosphaturic hormone and acts as a regulator of phosphate homeostasis [46]. It mediates its actions by binding to its cofactor alpha-Klotho and FGFreceptor 1 (FGFR1), through which it inhibits phosphate reabsorption in the kidney via downregulation of the sodium-dependent phosphate transporters (NaPi-2a and $\mathrm{NaPi}-2 \mathrm{c}$ ) in proximal renal tubules [55]. Additionally, it suppresses renal 1a-hydroxylase (CYP27B1) and activates 24-hydroxylase (CYP24A1), both of which contribute to lowering serum concentrations of 1,25-dihydroxy cholecalciferol and thus reduce intestinal uptake of phosphate [55]. The elimination of burosumab follows the endogenous immunoglobulin degradation pathway [56].

In early 2018, burosumab was approved by the EMA and the FDA for XLH in children aged 1 year or older until the cessation of linear growth $[56,57]$. Before starting burosumab treatment, supplementation with phosphate and active vitamin D should be stopped. In children, it is given subcutaneously every 2 weeks, which is much more convenient and should result in improved compliance compared to multiple daily doses of phosphate and vitamin D3. The recommended starting dose of burosumab is $0.4 \mathrm{mg} / \mathrm{kg}$ body weight every 2 weeks [ 53, 58]. In several phase 2 open-label trials in children with $\mathrm{XLH}$, burosumab improved phosphate homeostasis with normalization of phosphaturia and significantly reduced rickets severity score (RSS) [52, 59]. It decreased pain score and improved mobility function in a recent phase 3 study $[53,60]$. In another phase 3 study (study identifier
NCT02915705) burosumab treatment was superior to conventional therapy regarding growth velocity and disease progression determined by RSS [49]. An interesting point of view on burosumab efficacy was reported by Brenner et al. [61] using bioelectrical impedance analysis they determined improved body composition (increased fat-free mass) after 6 and 12 months of burosumab treatment. The effectiveness and safety of very early use of burosumab in children less than 1 year are currently being studied (study identifier NCT04188964).

Adverse events were more frequently reported in patients treated with burosumab compared to the conventional treatment [49]. However, it is generally well-tolerated and adverse events are mild and transient [53]. The most common side effects are local reactions at the site of injection (such as itching, pain, erythema, or bruising), cough, headache, fever, arthralgias, diarrhea, constipation, and nausea [52]. Possible increased risk for dental caries and dental abscess in children needs further evaluation [62]. Pathologic tissue calcification was one of the feared potential severe adverse events of burosumab treatment. Transient hypercalcemia was however rare, nephrocalcinosis due to calciuria under treatment with burosumab was not reported and transient hypercalcemia with pathological cardiac calcifications was described in one adult patient $[49,54]$. The long-term safety of burosumab is being longitudinally studied in XLH patients of all ages (study identifier NCT03651505).

\section{Achondroplasia}

Achondroplasia $(\mathrm{ACH})$ is the most common form of skeletal dysplasia characterized by disproportionate rhizomelic short stature, hypoplasia of the midface, and macrocephaly. Numerous orthopedic and neurological complications are associated with the disease [63]. Recently, comprehensive meta-analyses estimated its worldwide prevalence of 4.6 per 100,000 births. Large regional variations have been reported with the highest $\mathrm{ACH}$ prevalence in North Africa and the Middle East [64]. Prevalence in Europe has been estimated to be 3.62-3.72 per 100,000 births [64, 65].

$\mathrm{ACH}$ is caused by a gain-of-function mutation in the FGFR3 gene, a member of the tyrosine kinase receptor family [66]. The mutation is spontaneous in $80 \%$ of cases. $\mathrm{ACH}$ is inherited in an autosomal dominant manner and is characterized by full penetration, meaning that all individuals with the mutation have ACH. Excessive FGFR3 activation results in downstream activation of multiple 
intracellular signaling pathways, leading to intensified inhibition of cartilage tissue formation at the level of chondrocyte proliferation (via STAT1), hypertrophy, differentiation, and synthesis of the extracellular matrix (via ErkMAPK signaling pathway) [67]. The latter pathway has also been shown to be involved in premature synchondrosis closure and increased bone formation, leading to skeletal abnormalities (spinal canal stenosis, foramen magnum stenosis, and cranial base hypoplasia) which cause neurological problems in patients with $\mathrm{ACH}$ [68].

Therapy options for $\mathrm{ACH}$ are limited. Active followup and symptomatic treatment of the complications present the forefront of patient management. Growth hormone supplementation has not shown promising results and is not viewed as a standard treatment for $\mathrm{ACH}$. The progress in the understanding of $\mathrm{ACH}$ pathogenesis has led to the development of many potential therapeutic strategies for modulating excessive FGFR3 activation (Table 1). Approaches are varied and include inhibiting the tyrosine kinase activity of FGFR3 (infigratinib), producing artificial FGFR3 as a decoy for FGF ligand (recifercept), inhibition of FGFR3 downstream signaling pathways (meclizine, C-type natriuretic peptide [CNP] analogs), modulation of growth via natriuretic peptide receptor 2 (NPR2) receptor (CNP analogs) and use of aptamers or monoclonal antibodies to prevent binding of FGF to its receptor (aptamer RBM-007, vofatamab). The investigations into analogs of CNP, especially vosoritide, are currently the most advanced [69].

\section{Vosoritide}

Vosoritide is a recombinant CNP analog. Endogenous $\mathrm{CNP}$ and its action on the growth plate through NPR-B are recognized as one of the important regulating mechanisms of longitudinal bone growth. Coupled with NPR-B, CNP antagonizes downstream FGFR3 signaling by inhibiting the Erk-MAPK signaling pathway at the level of Raf. This leads to chondrocyte proliferation, differentiation and increases the extracellular matrix synthesis [70]. CNP-targeted overexpression in the cartilage or its continuous delivery by intravenous infusion has shown normalization of the impaired bone growth in mouse models with $\mathrm{ACH}[70,71]$. Endogenous $\mathrm{CNP}$ has a short half-life of 2-3 min, as it is rapidly degraded by neutral endopeptidase [72]. Vosoritide is more resistant to the action of neutral endopeptidase and has an extended half-life of approximately 15-20 min [73].

Preclinical studies in healthy mice and cynomolgus monkeys have shown the efficacy of daily subcutaneous vosoritide applications on endochondral bone growth stimulation without causing significant changes in bone quality parameters [74]. In August 2021, results of the extension phase 3 clinical trial in children with $\mathrm{ACH}$ aged between 5 and 18 , receiving vosoritide $15 \mu \mathrm{g} / \mathrm{kg}$ once daily in subcutaneous injection, were published. An increase in annualized growth velocity was observed, with $3.52 \mathrm{~cm}$ of height gain over a 2-year treatment period in comparison to untreated patients. In addition, improvement in the proportionality of body segments and no acceleration of the bone maturation process (determined by bone age assessment) was observed [75]. No serious adverse effects were reported; however, mild adverse effects such as reactions at the injection site occurred in up to $73 \%$ of patients, and in $23 \%$ mild, transient, in majority asymptomatic hypotension was observed after vosoritide application [76]. Due to the possibility of transient hypotension after treatment administration, current recommendations include hydration $30 \mathrm{~min}$ before vosoritide injection [77]. Vosoritide was approved by both EMA and FDA for the treatment of ACH in children from the age of 2 years until their growth plates are closed $[78,79]$. Vosoritide's effect on final adult height and prevention of neurological and orthopedic complications requiring surgical interventions is yet to be established. Current ongoing trials investigating its safety and efficacy in infants, young children, and those at risk of requiring cervicalmedullary decompression surgery, will provide further insights into treatment effects on growth, proportionality, and other medical complications of ACH [80].

\section{TransCon CNP}

TransCon CNP is an investigational prodrug of CNP designed for the treatment of ACH in children. In TransCon CNP, CNP is conjugated via a cleavable linker to a polyethylene glycol carrier molecule that prolongs CNP's half-life to $90 \mathrm{~h}$. This prolongation is achieved by increased resistance to the action of neutral endopeptidase and minimizing renal clearance. The cleavage process results in slow, sustained CNP release, leading to continuous exposure of CNP at the growth plate. Its long half-life also allows convenient weekly subcutaneous administrations [81].

Recent preclinical data in healthy cynomolgus monkeys showed that treatment with TransCon CNP subcutaneously once per week resulted in significant growth increases in body, tail, and long bones compared to controls. An increase in height was also more pronounced in comparison to the animals receiving a daily dose of $\mathrm{CNP}$ analog with the same amino acid sequence as vosoritide ( $5 \%$ vs. $3 \%$, respectively), and no significant changes in 
bone quality were observed with both treatments. Moreover, sustained CNP release resulted in lower systemic CNP peak levels and has not been associated with adverse cardiovascular effects in monkeys treated with repeated weekly doses up to $100 \mu \mathrm{g} / \mathrm{kg}$ [81]. The safe cardiovascular profile has also been recently confirmed in the first human clinical trial in healthy adult males receiving single doses of TransCon CNP up to $150 \mu \mathrm{g} / \mathrm{kg}$ [82]. Phase 2 of the TransCon CNP clinical trial to assess its safety, tolerability, and effect on annual growth velocity started in June 2020 is still ongoing. TransCon CNP will be administered subcutaneously once per week for 52 weeks in children with $\mathrm{ACH}$ aged 2-10 years (study identifier NCT04085523).

\section{Conclusion}

Several novel treatment options for childhood bone disorders were presented (Table 1). The common denominators of these treatments are novel, efficient, pos- sibly more etiology-based, and convenient treatment schemes. Long-term efficiency and safety will, however, need to be established.

\section{Conflict of Interest Statement}

Lecture fees were received from Kyowa Kirin, Pfizer, and Novo Nordisk by P.K. M.K. and S.J. have no conflicts of interest to declare.

\section{Funding Sources}

No funding relevant to the preparation of this manuscript was received by the authors.

\section{Author Contributions}

S.J., M.K., and P.K. equally contributed to the conception and design of the manuscript.

\section{References}

1 Bishop N, Arundel P, Clark E, Dimitri P, Farr J, Jones $\mathrm{G}$, et al. Fracture prediction and the definition of osteoporosis in children and adolescents: the ISCD 2013 pediatric official positions. J Clin Densitom. 2014 Apr;17(2):27580.

2 Ward LM, Weber DR, Munns CF, Högler W, Zemel BS. A contemporary view of the definition and diagnosis of osteoporosis in children and adolescents. J Clin Endocrinol Metab. 2020 May; 105(5):e2088-97.

3 Mok CC, Wong SN, Ma KM. Childhood-onset disease carries a higher risk of low bone mineral density in an adult population of systemic lupus erythematosus. Rheumatology. 2012 Mar;51(3):468-75.

4 Rizzoli R, Bianchi ML, Garabédian M, McKay HA, Moreno LA. Maximizing bone mineral mass gain during growth for the prevention of fractures in the adolescents and the elderly. Bone. 2010 Feb;46(2):294-305.

5 Brunetti G, D'Amato G, Chiarito M, Tullo A, Colaianni G, Colucci S, et al. An update on the role of RANKL-RANK/osteoprotegerin and WNT-B-catenin signaling pathways in pediatric diseases. World J Pediatr. 2019 Feb; 15(1):4-11

6 Nasomyont N, Gordon CM. Osteoporosis in childhood and adolescence. In: Marcus and feldman's osteoporosis: Elsevier; 2021. p. 911-50.

7 Fintini D, Cianfarani S, Cofini M, Andreoletti A, Ubertini GM, Cappa M, et al. The bones of children with obesity. Front Endocrinol. 2020 Apr 24;11:200.
8 Munns CF, Shaw N, Kiely M, Specker BL, Thacher TD, Ozono K, et al. Global consensus recommendations on prevention and management of nutritional rickets. Horm Res Paediatr. 2016;85(2):83-106.

9 Hanley DA, Adachi JD, Bell A, Brown V. Denosumab: mechanism of action and clinical outcomes. Int J Clin Pract. 2012 Dec;66(12): 1139-46.

10 Simonet WS, Lacey DL, Dunstan CR, Kelley M, Chang MS, Lüthy R, et al. Osteoprotegerin: a novel secreted protein involved in the regulation of bone density. Cell. 1997;89(2): 309-19.

11 Anastasilakis AD, Polyzos SA, Makras P. Therapy of endocrine disease: denosumab versus bisphosphonates for the treatment of postmenopausal osteoporosis. Eur J Endocrinol. 2018 Jul;179(1):R31-45.

12 Kendler DL, Roux C, Benhamou CL, Brown JP, Lillestol M, Siddhanti S, et al. Effects of denosumab on bone mineral density and bone turnover in postmenopausal women transitioning from alendronate therapy. J Bone Miner Res. 2010 Jan;25(1):72-81.

13 Papapoulos SE, Cremers SC. Prolonged bisphosphonate release after treatment in children. N Engl J Med. 2007 Mar;356(10): 1075-6.

14 Block GA, Bone HG, Fang L, Lee E, Padhi D. A single-dose study of denosumab in patients with various degrees of renal impairment. J Bone Miner Res. 2012 Jul;27(7):1471-9.

15 European Medicines Agency. Xgeva [cited 2021 Nov 5]. Available from: https://www.
ema.europa.eu/en/medicines/human/EPAR/ xgeva.

16 U.S. Food And Drug Association. Xgeva Label [cited 2021 Nov 5]. Available from: https:// www.accessdata.fda.gov/drugsatfda_docs/ label/2013/125320s094lbl.pdf.

17 Boyce AM. Denosumab: an emerging therapy in pediatric bone disorders. Curr Osteoporos Rep. 2017 Aug;15(4):283-92.

18 Hoyer-Kuhn H, Rehberg M, Netzer C, Schoenau E, Semler O. Individualized treatment with denosumab in children with osteogenesis imperfecta: follow up of a trial cohort. Orphanet J Rare Dis. 2019 Dec;14(1):219.

19 Trejo P, Rauch F, Ward L. Hypercalcemia and hypercalciuria during denosumab treatment in children with osteogenesis imperfecta type VI. J Musculoskelet Neuronal Interact. 2018; 18(1):76-80.

20 Hoyer-Kuhn H, Franklin J, Allo G, Kron M, Netzer C, Eysel P, et al. Safety and efficacy of denosumab in children with osteogenesis imperfect - a first prospective trial. J Musculoskelet Neuronal Interact. 2016 Mar;16(1):24-32.

21 Anastasilakis AD, Makras P, Doulgeraki A, Polyzos SA, Guarnieri V, Papapoulos SE. Denosumab for the treatment of primary pediatric osteoporosis. Osteoporos Int. 2021 Nov; 32(11):2377-81.

22 Huang TH, Liu HC, Hou JY, Chang CY, Sun FJ, Yeh TC. Efficacy and safety of denosumab therapy for low bone mineral density in childhood cancer survivors: a report of preliminary experience. Pediatr Blood Cancer. 2019 Oct;66(10):e27927. 
23 Boyce AM, Chong WH, Yao J, Gafni RI, Kelly $\mathrm{MH}$, Chamberlain CE, et al. Denosumab treatment for fibrous dysplasia. J Bone Mineral Res. 2012 Jul;27(7):1462-70.

24 Ferriero K, Shah B, Yan Y, Khatri S, Caccamese J, Napoli JA, et al. Case report: safety and efficacy of denosumab in four children with Noonan syndrome with multiple giant cell lesions of the jaw. Front Pediatr. 2020 Sep; 8:515.

25 Grasemann C, Schündeln MM, Hövel M, Schweiger B, Bergmann C, Herrmann R, et al. Effects of RANK-ligand antibody (Denosu$\mathrm{mab}$ ) treatment on bone turnover markers in a girl with Juvenile Paget's disease. J Clin Endocrinol Metab. 2013 Aug;98(8):3121-6.

26 Lange T, Stehling C, Fröhlich B, Klingenhöfer M, Kunkel P, Schneppenheim R, et al. Denosumab: a potential new and innovative treatment option for aneurysmal bone cysts. Eur Spine J. 2013 Jun;22(6):1417-22.

27 Pelle DW, Ringler JW, Peacock JD, Kampfschulte K, Scholten DJ, Davis MM, et al. Targeting receptor-activator of nuclear kappaB ligand in aneurysmal bone cysts: verification of target and therapeutic response. Transl Res. 2014 Aug;164(2):139-48.

28 Upfill-Brown A, Bukata S, Bernthal NM, Felsenfeld AL, Nelson SD, Singh A, et al. Use of denosumab in children with osteoclast bone dysplasias: report of three cases. JBMR Plus. 2019 Aug;3(10):e10210.

29 Wang HD, Boyce AM, Tsai JY, Gafni RI, Farley FA, Kasa-Vubu JZ, et al. Effects of denosumab treatment and discontinuation on human growth plates. J Clin Endocrinol Metab. 2014 Mar;99(3):891-7.

30 Cummings SR, Martin JS, McClung MR, Siris ES, Eastell R, Reid IR, et al. Denosumab for prevention of fractures in postmenopausal women with osteoporosis. N Engl J Med. 2009 Aug;361(8):756-65.

31 Iranikhah M, Deas C, Murphy P, Freeman MK. Effects of denosumab after treatment discontinuation: a review of the literature. Consult Pharm. 2018 Mar;33(3):142-51.

32 Deodati A, Fintini D, Levtchenko E, Rossi M, Ubertini G, Segers H, et al. Mechanisms of acute hypercalcemia in pediatric patients following the interruption of denosumab. J Endocrinol Invest. 2021 Jan;45(1):159-66.

33 Dunnion S, Paterson A, Johnston R. Dense sclerotic metaphyseal bands caused by denosumab therapy. Pediatr Radiol. 2020 May; 50(6):877-8.

34 Qi WX, Tang LN, He AN, Yao Y, Shen Z. Risk of osteonecrosis of the jaw in cancer patients receiving denosumab: a meta-analysis of seven randomized controlled trials. Int J Clin Oncol. 2014 Apr;19(2):403-10.

35 Selga J, Nuñez JH, Minguell J, Lalanza M, Garrido M. Simultaneous bilateral atypical femoral fracture in a patient receiving denosumab: case report and literature review. Osteoporos Int. 2016 Feb;27(2):827-32.
36 Uday S, Gaston CL, Rogers L, Parry M, Joffe $\mathrm{J}$, Pearson J, et al. Osteonecrosis of the jaw and rebound hypercalcemia in young people treated with denosumab for giant cell tumor of bone. J Clin Endocrinol Metab. 2018 Feb; 103(2):596-603.

37 Brömme D, Lecaille F. Cathepsin K inhibitors for osteoporosis and potential off-target effects. Expert Opin Investig Drugs. 2009 May; 18(5):585-600.

38 Duong LT, Crawford R, Scott K, Winkelmann CT, Wu G, Szczerba P, et al. Odanacatib, effects of 16-month treatment and discontinuation of therapy on bone mass, turnover and strength in the ovariectomized rabbit model of osteopenia. Bone. 2016 Dec;93:86-96.

39 Cusick T, Chen CM, Pennypacker BL, Pickarski M, Kimmel DB, Scott BB, et al. Odanacatib treatment increases hip bone mass and cortical thickness by preserving endocortical bone formation and stimulating periosteal bone formation in the ovariectomized adult rhesus monkey. J Bone Miner Res. 2012 Mar; 27(3):524-37.

40 Masarachia PJ, Pennypacker BL, Pickarski M, Scott KR, Wesolowski GA, Smith SY, et al. Odanacatib reduces bone turnover and increases bone mass in the lumbar spine of skeletally mature ovariectomized rhesus monkeys. J Bone Miner Res. 2012 Mar;27(3):50923.

41 Duong LT. Therapeutic inhibition of cathepsin K-reducing bone resorption while maintaining bone formation. Bonekey Rep. 2012 May; $1: 67$

42 Rizzoli R, Benhamou CL, Halse J, Miller PD, Reid IR, Rodríguez Portales JA, et al. Continuous treatment with odanacatib for up to 8 years in postmenopausal women with low bone mineral density: a phase 2 study. Osteoporos Int. 2016 Jun;27(6):2099-107.

43 McClung MR, O’Donoghue ML, Papapoulos SE, Bone H, Langdahl B, Saag KG, et al. Odanacatib for the treatment of postmenopausal osteoporosis: results of the LOFT multicentre, randomised, double-blind, placebo-controlled trial and LOFT extension study. Lancet Diabetes Endocrinol. 2019 Dec;7(12): 899-911.

44 Gentile C, Chiarelli F. Rickets in children: an update. Biomedicines. 2021 Jun;9(7):738

45 Beck-Nielsen SS, Brock-Jacobsen B, Gram J, Brixen $\mathrm{K}$, Jensen TK. Incidence and prevalence of nutritional and hereditary rickets in southern Denmark. Eur J Endocrinol. 2009 Mar;160(3):491-7.

46 Quarles LD. FGF23, PHEX, and MEPE regulation of phosphate homeostasis and skeletal mineralization. Am J Physiol Endocrinol Metab. 2003 Jul;285(1):E1-9.

47 Padidela R, Nilsson O, Nilsson O, Makitie O, Beck-Nielsen S, Ariceta G, et al. The international X-linked hypophosphataemia (XLH) registry (NCT03193476): rationale for and description of an international, observational study. Orphanet J Rare Dis. 2020 Jun;15(1): 172.
48 Mao M, Carpenter TO, Whyte MP, Skrinar A, Chen CY, San Martin J, et al. Growth curves for children with X-linked hypophosphatemia. J Clin Endocrinol Metab. 2020 Oct; 105(10):3243-9.

49 Imel EA, Glorieux FH, Whyte MP, Munns CF, Ward LM, Nilsson O, et al. Burosumab versus conventional therapy in children with $\mathrm{X}$-linked hypophosphataemia: a randomised, active-controlled, open-label, phase 3 trial. Lancet. 2019 Jun;393(10189):2416-27.

50 Raimann A, Mindler GT, Kocijan R, Bekes K, Zwerina J, Haeusler G, et al. Multidisciplinary patient care in X-linked hypophosphatemic rickets: one challenge, many perspectives. Wien Med Wochenschr. 2020 Apr;170(5-6) $116-23$.

51 Schindeler A, Biggin A, Munns CF. Clinical evidence for the benefits of burosumab therapy for X-linked hypophosphatemia (XLH) and other conditions in adults and children. Front Endocrinol. 2020 May;11:338.

52 Carpenter TO, Imel EA, Holm IA, Jan De Beur SM, Insogna KL. A clinician's guide to X-linked hypophosphatemia. J Bone Miner Res. 2011 Jul;26(7):1381-8.

53 Haffner D, Emma F, Eastwood DM, Duplan MB, Bacchetta J, Schnabel D, et al. Clinical practice recommendations for the diagnosis and management of X-linked hypophosphataemia. Nat Rev Nephrol. 2019 Jul;15(7):43555.

54 Harada D, Ueyama K, Oriyama K, Ishiura Y, Kashiwagi $\mathrm{H}$, Yamada $\mathrm{H}$, et al. Switching from conventional therapy to burosumab injection has the potential to prevent nephrocalcinosis in patients with X-linked hypophosphatemic rickets. J Pediatr Endocrinol Metab. 2021 Apr;34(6):791-8.

55 Richter B, Faul C. FGF23 actions on target tissues-with and without Klotho. Front Endocrinol. 2018 May;9:189.

56 European Medicines Agency. Crysvita [cited 2021 Oct 16]. Available from: https://www. ema.europa.eu/en/medicines/human/EPAR/ crysvita.

57 U.S. Food And Drug Association. FDA approves first therapy for rare inherited form of rickets, X-linked hypophosphatemia [cited 2021 Oct 16]. Available from: https://www. fda.gov/news-events/press-announcements/ fda-approves-first-therapy-rare-inheritedform-rickets- $x$-linked-hypophosphatemia.

58 Carpenter TO, Whyte MP, Imel EA, Boot AM, Högler W, Linglart A, et al. Burosumab therapy in children with X-linked hypophosphatemia. New Engl J Med. 2018 May; 378(21):1987-98.

59 Whyte MP, Carpenter TO, Gottesman GS, Mao M, Skrinar A, San Martin J, et al. Efficacy and safety of burosumab in children aged 1-4 years with X-linked hypophosphataemia: a multicentre, open-label, phase 2 trial. Lancet Diabetes Endocrinol. 2019 Mar;7(3):189-99. 
60 Padidela R, Whyte MP, Glorieux FH, Munns CF, Ward LM, Nilsson O, et al. Patient-reported outcomes from a randomized, activecontrolled, open-label, phase 3 trial of burosumab versus conventional therapy in children with X-linked hypophosphatemia. Calcif Tissue Int. 2021 May;108(5):622-33.

61 Brener A, Lebenthal Y, Cleper R, Kapusta L, Zeitlin L. Body composition and cardiometabolic health of pediatric patients with $\mathrm{X}$ linked hypophosphatemia (XLH) under burosumab therapy. Ther Adv Endocrinol Metab. 2021 Mar;12:20420188211001150.

62 Baroncelli GI, Mora S. X-linked hypophosphatemic rickets: multisystemic disorder in children requiring multidisciplinary management. Front Endocrinol. 2021 Aug;12:688309.

63 Horton WA, Hall JG, Hecht JT. Achondroplasia. Lancet. 2007 Jul;370(9582):162-72.

64 Foreman PK, Kessel F, Hoorn R, Bosch J, Shediac R, Landis S. Birth prevalence of achondroplasia: a systematic literature review and meta-analysis. Am J Med Genet A. 2020 Oct; 182(10):2297-316.

65 Coi A, Santoro M, Garne E, Pierini A, Addor $\mathrm{M}$, Alessandri J, et al. Epidemiology of achondroplasia: a population-based study in Europe. Am J Med Genet A. 2019 Sep;179(9): $1791-8$.

66 Rousseau F, Bonaventure J, Legeai-Mallet L, Pelet A, Rozet JM, Maroteaux P, et al. Mutations in the gene encoding fibroblast growth factor receptor-3 in achondroplasia. Nature. 1994 Sep;371(6494):252-4.

67 Kim JM, Yang YS, Park KH, Oh H, Greenblatt $\mathrm{MB}$, Shim JH. The ERK MAPK pathway is essential for skeletal development and homeostasis. Int J Mol Sci. 2019 Apr;20(8):1803.

68 Matsushita T, Wilcox WR, Chan YY, Kawanami A, Bukulmez $\mathrm{H}$, Balmes $\mathrm{G}$, et al. FGFR3 promotes synchondrosis closure and fusion of ossification centers through the MAPK pathway. Hum Mol Genet. 2008 Oct;18(2): $227-40$.
69 Wrobel W, Pach E, Ben-Skowronek I. Advantages and disadvantages of different treatment methods in achondroplasia: a review. Int J Mol Sci. 2021 May;22(11):5573.

70 Yasoda A, Kitamura H, Fujii T, Kondo E, Murao N, Miura M, et al. Systemic administration of C-type natriuretic peptide as a novel therapeutic strategy for skeletal dysplasias. Endocrinology. 2009 Jul;150(7):3138-44.

71 Yasoda A, Komatsu Y, Chusho H, Miyazawa T, Ozasa A, Miura M, et al. Overexpression of $\mathrm{CNP}$ in chondrocytes rescues achondroplasia through a MAPK-dependent pathway. Nat Med. 2004 Jan;10(1):80-6.

72 Peake NJ, Hobbs AJ, Pingguan-Murphy B, Salter DM, Berenbaum F, Chowdhury TT. Role of C-type natriuretic peptide signalling in maintaining cartilage and bone function. Osteoarthritis Cartilage. 2014 Nov;22(11): $1800-7$.

73 Lorget F, Kaci N, Peng J, Benoist-Lasselin C, Mugniery E, Oppeneer T, et al. Evaluation of the therapeutic potential of a CNP analog in a Fgfr3 mouse model recapitulating achondroplasia. Am J Hum Genet. 2012 Dec;91(6): 1108-14.

74 Wendt DJ, Dvorak-Ewell M, Bullens S, Lorget F, Bell SM, Peng J, et al. Neutral endopeptidase-resistant C-type natriuretic peptide variant represents a new therapeutic approach for treatment of fibroblast growth factor receptor 3-related dwarfism. J Pharmacol Exp Ther. 2015 Apr;353(1):132-49.

75 Savarirayan R, Tofts L, Irving M, Wilcox WR, Bacino CA, Hoover-Fong J, et al. Safe and persistent growth-promoting effects of vosoritide in children with achondroplasia: 2-year results from an open-label, phase 3 extension study. Genet Med. 2021 Dec;23(12):2443-7.

76 Savarirayan R, Tofts L, Irving M, Wilcox W, Bacino CA, Hoover-Fong J, et al. Once-daily, subcutaneous vosoritide therapy in children with achondroplasia: a randomised, doubleblind, phase 3, placebo-controlled, multicentre trial. Lancet. 2020 Sep;396(10252):684-92.
77 European Medicines Agency. Vosoritide: summary of product characteristics [cited 2021 Oct 22]. Available from: https://www. ema.europa.eu/en/documents/product-information/voxzogo-epar-product-information_en.pdf.

78 Biomarin. European commission approves BioMarin's VOXZOGO ${ }^{\infty}$ (vosoritide) for the treatment of children with achondroplasia from age 2 until growth plates close [cited 2021 Oct 19]. Available from: https://investors.biomarin.com/2021-08-27-EuropeanCommission-Approves-BioMarinsVOXZOGO-R-vosoritide-for-the-Treatment-of-Children-with-Achondroplasiafrom-Age-2-Until-Growth-Plates-Clos.

79 U.S. Food And Drug Association. FDA approves first drug to improve growth in children with most common form of dwarfism [cited 2021 Oct 19]. Available from: https://www.fda. gov/news-events/press-announcements/fdaapproves-first-drug-improve-growth-children-most-common-form-dwarfism.

80 Savarirayan R, Irving M, Maixner W, Thompson D, Offiah AC, Connolly DJA, et al. Rationale, design, and methods of a randomized, controlled, open-label clinical trial with openlabel extension to investigate the safety of vosoritide in infants, and young children with achondroplasia at risk of requiring cervicomedullary decompression surgery. Sci Prog. 2021;104(1):368504211003782.

81 Breinholt VM, Rasmussen CE, Mygind PH, Kjelgaard-Hansen M, Faltinger F, Bernhard A, et al. TransCon CNP, a sustained-release C-type natriuretic peptide prodrug, a potentially safe and efficacious new therapeutic modality for the treatment of comorbidities associated with fibroblast growth factor receptor 3-related skeletal dysplasias. J Pharmacol Exp Ther. 2019 Sep;370(3):459-71.

82 Bharucha K, Ota S, Christoffersen ED, Mygind P, Viuff D, Leff J, et al. Potential for a once weekly novel therapy in children with achondroplasia. Bone Abstracts. 2019 Jul. 